\title{
Depression, Diabetes and Dementia: Formaldehyde May Be a Common Causal Agent; Could Carnosine, a Pluripotent Peptide, Be Protective?
}

\author{
Alan R. Hipkiss \\ Aston Research Centre for Healthy Ageing (ARCHA), Aston University, Birmingham, B4 7ET, U.K
}

[Received December 2, 2016; Revised January 15, 2017; Accepted January 20, 2017]

Recent studies have highlighted the possible involvement of formaldehyde in a number of age-associated phenomena, dementia, depression and diabetes (type-2). Papers by Li et al. [1,2], Cui et al. [3], Tong et al. [4,5] and Mei et al. [6] have shown an association between formaldehyde and age-related dysfunction such as glaucoma, stroke, Alzheimer's disease and memory decline. Furthermore, Tulpule and colleagues $[7,8]$ have demonstrated that formaldehyde strongly stimulates glycolytic flux in astrocytes and neurones, implying its contribution to metabolic age-related dysfunction, (e.g. type-2 diabetes, memory loss and neurodegeneration). Formaldehyde is thought to induce macromolecular dysfunction, at least in part, via its ability to crosslink protein to DNA [9].

Although formaldehyde-induced toxicity is not an entirely a new idea, it has been suggested that the presence of formaldehyde in the brain has been over-looked as either causative or a consequence of other underlying and deleterious phenomena $[10,11]$. Furthermore, given that current research indicates that excessive glycolytic activity may be an important contributor to not only type2 diabetes but also to neurodegenerative conditions, it is perhaps relevant to note that formate, a product of formaldehyde metabolism, has been shown to enhance glycolytic flux in cultured astrocytes and neurones but inhibit mitochondrial respiration $[7,8]$. Other studies have shown that formaldehyde's effects on norepinephrine are mediated by direct reaction with the hormone, thus decreasing hormone availability [6] and thereby contributing to age-related memory decline.

It has been found that the carbonyl scavengers, aminoguanidine and resveratrol, are effective in suppressing the effects of formaldehyde [12], but due to its toxicity, aminoguanidine is unlikely to be employed therapeutically, and resveratrol has also been described as a formaldehyde donor [13]. The naturally-occurring, pluripotent dipeptide, carnosine can also suppress the cross-linking activity of formaldehyde [14], most probably by reacting directly with it. More recently, carnosine has been shown to be protective in rats exposed to formaldehyde [15]. It is also interesting to note that increased levels of endogenous formaldehyde are present in the brains of the senescence accelerated mouse strain, SAMP8, at 3 months of age [16]. In earlier studies, dietary supplementation with carnosine has been shown to delay the onset of age-related changes in another senescence accelerated mouse strain (SAMP1) as well as suppress brain mitochondrial monoamine oxidase activity [17]. Thus, carnosine's beneficial effects on the SAMP1 mice might be explained, at least in part, not only by the dipeptide's reactivity towards formaldehyde, but also by suppressing amine oxidase-mediated formaldehyde generation from methylamine.

Carnosine has also been shown to suppress glycolysis $[18,19]$ but stimulate mitochondrial activity in various model cell systems [20-23] and delay cell senescence in cultured human fibroblasts [24]. Given

*Correspondence should be addressed to: Dr. Alan R. Hipkiss, Aston Research Centre for Healthy Ageing (ARCHA), Aston University, Birmingham, B4 7ET, U.K. Email: alanandjill@lineone.net

Copyright: ( ) 2017. This is an open-access article distributed under the terms of the Creative Commons Attribution License (CC BY 4.0), which permits unrestricted use, distribution, and reproduction in any medium, provided the original author and source are credited. 
carnosine's well-characterized ability to scavenge a variety of deleterious aldehydes, including methylglyoxal (MG) $[25,26]$ the toxic by-product of excessive glycolysis responsible for much macromolecular modification associated with the secondary complications of type- 2 diabetes, it is suggested that carnosine, a relatively nontoxic dipeptide, could be explored for its protective activity against reactive carbonyl compounds generally and formaldehyde in particular. Additionally, carnosine's ability to inhibit regional brain monoamine-oxidase activity [27] could contribute to its antidepressant actions [28] by maintaining norepinephrine levels [29] by suppressing formaldehyde generation [30].

That Alzheimer's disease, depression and type- 2 diabetes may exhibit common metabolic features associated with increased formaldehyde generation, and which carnosine could ameliorate, directly or indirectly, suggests that its efficacy should be explored with respect to these age-related conditions. Administration via a nasal route could be a useful method to escape the effects of serum carnosinase, especially as the olfactory lobe is normally enriched in carnosine and loss of a sense of smell is frequently an early symptom of neurodegeneration. However, dietary supplementation with carnosine, especially if the related peptide anserine is also present, has been shown to improve aspects of brain function (behaviour, cognition and well-being) in a number of double-blind, placebo-controlled, human studies [31-36], which begins to question whether serum carnosinase is a major impediment to the dipeptide's potential efficacy.

In summary, it has been shown that raised tissue levels of formaldehyde are associated with depression, neurodegeneration and type- 2 diabetes. It is suggested that administration of the naturally-occurring dipeptide carnosine may exert alleviative effects on depression and memory by helping to maintain norepinephrine levels due to (i) inhibiting formaldehyde synthesis from methylamine via its action on monoamine oxidase, and (ii) scavenging formaldehyde, thereby decreasing norepinephrine inactivation. Both type- 2 diabetes and Alzheimer's disease are associated with enhanced protein glycation mediated mostly by MG, a glycolytic byproduct. Carnosine's formaldehyde scavenging activity will decrease formate synthesis, which would otherwise stimulate glycolysis, while the dipeptide's suppressive effects on glycolysis together with its ability to scavenge MG, will decrease the potential for MG-mediated protein modification which characterises age-related protein dysfunction in type-2 diabetes and Alzheimer's disease. (See Table 1 for concise summary). It is therefore suggested that various forms of carnosine therapy should be explored [37].
Table 1. Summary of the putative beneficial effects of carnosine on formaldehyde-mediated changes associated with depression, Alzheimer's disease and type-2 diabetes.

\begin{tabular}{|c|c|c|}
\hline Condition & $\begin{array}{l}\text { Characteristic/possible } \\
\text { protective mechanism }\end{array}$ & Refs. \\
\hline \multicolumn{3}{|l|}{ Depression } \\
\hline No carnosine & $\begin{array}{l}\text { Increased } \mathrm{HCHO} \text { and } \\
\text { norepinephrine inactivation }\end{array}$ & {$[2,6,9]$} \\
\hline \multirow[t]{2}{*}{ Plus carnosine } & HCHO scavenging. & {$[14]$} \\
\hline & $\begin{array}{l}\text { Decreased HCHO formation } \\
\text { by inhibition of SSAO } \\
\text { mediated methylamine } \\
\text { oxidation thus raising } \\
\text { norepinephrine activity }\end{array}$ & [17] \\
\hline \multicolumn{3}{|l|}{$A D \& T 2 D$} \\
\hline \multirow[t]{3}{*}{ No carnosine } & $\begin{array}{l}\text { Increased } \mathrm{HCHO} \text { and } \\
\text { increased glycolysis }\end{array}$ & {$[3,4]$} \\
\hline & $\begin{array}{l}\text { Increased MG-mediated } \\
\text { protein glycation }\end{array}$ & {$[5,7]$} \\
\hline & Mitochondrial dysfunction & {$[10,11]$} \\
\hline \multirow[t]{4}{*}{ Plus carnosine } & $\begin{array}{l}\text { Decreased glycolysis and } \\
\text { decreased protein glycation } \\
\text { due to decreased formate } \\
\text { synthesis }\end{array}$ & {$[15,17]$} \\
\hline & $\begin{array}{l}\text { and direct inhibitory effects } \\
\text { on glycolysis. }\end{array}$ & {$[18,19]$} \\
\hline & $\begin{array}{l}\text { MG and HCHO scavenging } \\
\text { decreases glycation }\end{array}$ & {$[14,26]$} \\
\hline & $\begin{array}{l}\text { Increased mitochondrial } \\
\text { activity }\end{array}$ & {$[20,21,23]$} \\
\hline
\end{tabular}

\section{References}

[1] Li T, Su T, He Y. et al. (2016). Brain formaldehyde is related to water intake behaviour. Aging Dis, 7:561-584.

[2] Li Y, Song Z, Ding Y. et al. (2016). Effects of formaldehyde exposure on anxiety-like and depressionlike behaviour, cognition, central levels of glucocorticoid receptor and tyrosine hydrolase in mice. Chemosphere, 144:2004-12.

[3] Cui Y, Su TG, Zhang SD. et al. (2016). Elevated urine formaldehyde in elderly patients with primary open angle glaucoma. Int J Ophthalmol, 9:411-16.

[4] Tong Z, Wang W, Luo W. et al. (2017). Urine formaldehyde predicts cognitive impairment in poststroke dementia and Alzheimer's disease. J Alzheimer's Dis, 55:1031-1038

[5] Tong Z, Han C, Qiang M. et al. (2015). Age-related formaldehyde interferes with DNA methyltransferase function, causing memory loss in Alzheimer's disease. Neurobiol. Aging, 36:100-10.

[6] Mei Y, Jiang C, Wan Y. et al. (2015). Aging-associated formaldehyde-induced norepinephrine deficiency contributes to age-related memory decline. Aging Cell, 14: 659-68. 
[7] Tulpule K, Dringen R (2012). Formate generated by cellular oxidation of formaldehyde accelerates the glycolytic flux in cultured astrocytes. Glia, 60:582-93.

[8] Tulpule K, Hohnholt MC, Dringen R (2013). Formaldehyde metabolism and formaldehyde-induced stimulation of lactate and glutathione export in cultured neurons. J Neurochem, 125:260-72.

[9] Gubisne-Naberle D, Hill W, Kazachkov M. et al. (2004). Protein cross-linkage induced by formaldehyde derived from semicarbazide-sensitive amino oxidase-mediated deamination of methylamine. J Pharmacol Exp Ther, 310:1125-32.

[10] Tulpule K, Dringen R (2013). Formaldehyde in the brain: an overlooked player in neurodegeneration? J. Neurochem, 127:7-21.

[11] Rizak JD, Ma Y, Hu X (2014). Is formaldehyde the missing link in AD pathology? The differential aggregation of amyloid-beta with APOE isoforms in vitro. Curr Alzheimer Res, 11: 461-8.

[12] Kazachkov M, Chen K, Babiy S, Yu PH (2007). Evidence for in vivo scavenging by aminoguanidine of formaldehyde produced via semicarbazide-sensitive amine oxidase-mediated deamination. J Pharmacol Exp Ther, 322: 1201-7.

[13] Szende B, Tyihak E (2010). Effect of formaldehyde on cell proliferation and death. Cell Biol Int, 34: 1273-82.

[14] Hipkiss, AR, Preston JE, Himsworth DTM, et al. (1998). Pluripotent protective effects of carnosine, a naturally occurring dipeptide. Ann New York Acad Sci, 854; $37-$ 53.

[15] Aydin S, Ogeturk M, Kuloglu T, et al. (2015). Effect of carnosine supplementation on apoptosis and irisin, total oxidant and antioxidant levels in the serum, liver, and lung tissues in rats exposed to formaldehyde inhalation. Peptides, 64: 14-23.

[16] Qiang M, Xiao R, Su T, et al. (2014). A novel mechanism for endogenous formaldehyde elevation in SAMP8 mouse. J Alzheimers Dis, 40:1039-53.

[17] Gallant S, Semyonova M. Yuneva M (2000). Carnosine as a potential anti-senescence drug. Biochem (Moscow) 65: 866-68.

[18] Iovine B, Iannella ML, Nocella F, et al. (2012). Carnosine inhibits KRAS-mediated HCT116 proliferation by affecting ATP and ROS production. Cancer Lett. 315:122-8.

[19] Renner C, Asperger A, Seyffarth A, et al. (2010). Carnosine inhibits ATP production in cells from malignant glioma. Neurol Res, 32:101-5.

[20] Baek SH, Noh AR, Kim KA, et al. (2014). Modulation of mitochondrial function and autophagy mediates carnosine neuroprotection against ischemic brain damage. Stroke, 45:2438-43.

[21] Macedo LW, Cararo JH, Maravai SG, et al. (2016). Acute Carnosine Administration Increases Respiratory Chain Complexes and Citric Acid Cycle Enzyme Activities in Cerebral Cortex of Young Rats. Mol Neurobiol, 53:5582-90.
[22] Davis CK, Laud PJ, Bahor Z, et al. (2016). Systematic review and stratified meta-analysis of the efficacy of carnosine in animal models of ischemic stroke. J Cereb Blood Flow Metab, 36:1686-1694.

[23] Cartwright SP, Bill RM, Hipkiss AR (2012). L-carnosine affects the growth of Saccharomyces cerevisiae in a metabolism-dependent manner. PLoS One. 7(9): e45006.

[24] McFarland GA, Holliday R (1994). Retardation of the senescence of cultured human diploid fibroblasts by carnosine. Exp Cell Res, 212:167-75.

[25] Colzani M, De Maddis D, Casali G, et al. (2016). Reactivity, Selectivity, and Reaction Mechanisms of Aminoguanidine, Hydralazine, Pyridoxamine, and Carnosine as Sequestering Agents of Reactive Carbonyl Species: A Comparative Study. Chem Med Chem 11: 1778-89.

[26] Hipkiss AR, Baye E, de Courten B (2016). Carnosine and the processes of ageing. Maturitas, 93:28-33.

[27] Banerjee S, Poddar MK (2015). Carnosine: effect on aging-induced increase in brain regional monoamine oxidase-A activity. Neurosci Res, 92: 62-70.

[28] Hipkiss AR. (2015). Possible benefit of dietary carnosine towards depressive disorders. Aging Dis, 6:300-3.

[29] Delgado PL, Moreno FA (2000). Role of norepinephrine in depression. J. Clin. Psychiatry, 61: Suppl 1: 5-11.

[30] Song MS, Baker GB, Dursun SM, Todd KG (2010). The antidepressant phenelzine protects neurons and astrocytes against formaldehyde-induced toxicity. J Neurochem, 114; 1405-13.

[31] Hisatsune T, Kaneko J, Kurashige H, et al. (2016). Effect of Anserine/Carnosine Supplementation on Verbal Episodic Memory in Elderly People. J Alzheimers Dis, 50:149-59.

[32] Lombardi C, Carubelli V, Lazzarini V, et al. (2015). Effects of oral administration of orodispersible levocarnosine on quality of life and exercise performance in patients with chronic heart failure. Nutrition, 31:72-8.

[33] Szcześniak D, Budzeń S, Kopeć W, Rymaszewska J. (2014). Anserine and carnosine supplementation in the elderly: Effects on cognitive functioning and physical capacity. Arch Gerontol Geriatr, 59:485-90.

[34] Chengappa KN, Turkin SR, DeSanti S, et al. (2012). A preliminary, randomized, double-blind, placebocontrolled trial of L-carnosine to improve cognition in schizophrenia. Schizophr Res, 142:145-52

[35] Baraniuk JN, El-Amin S, Corey R, et al. (2013). Carnosine treatment for gulf war illness: a randomized controlled trial. Glob J Health Sci, 5:69-81.

[36] Chez MG, Buchanan CP, Aimonovitch MC, et al. (2001). Double-blind, placebo-controlled study of Lcarnosine supplementation in children with autistic spectrum disorders. J Child Neurol, 17:833-7.

[37] Cararo JH, Streck EL, Schuck PF, Ferreira Gda C. (2015). Carnosine and Related Peptides: Therapeutic Potential in Age-Related Disorders. Aging Dis, 6:36979. 